\title{
Exploration of Blended Teaching Mode of Remote Sensing Principles Course Based on the Concept of Emerging Engineering Education
}

\author{
Yunjun Zhan ${ }^{1, \mathrm{a}}$, Lintong Sui ${ }^{1, \mathrm{~b}}$, Jiejun Huang ${ }^{1, \mathrm{c}}$, Yanbin Yuan ${ }^{1, \mathrm{~d}}$, Ming Zhang ${ }^{1, \mathrm{e}}$ and Xu \\ Zhang ${ }^{1, \mathrm{f}}$
}

\begin{abstract}
${ }^{1}$ School of Resources and Environmental Engineering, Wuhan University of Technology, Wuhan, Hubei, China
azhanyj@whut.edu.cn, ${ }^{b}$ suilintong@whut.edu.cn, ${ }^{c}$ hjj@whut.edu.cn, ${ }^{d} y y b j m @ 126 . c o m,{ }^{e}$ zhangming_1988@126.com,

${ }_{x . z h a n g 86 @ h o t m a i l . c o m}$
\end{abstract}

\begin{abstract}
Through years of teaching practice and full understanding of the current concept of emerging engineering education and the innovation of blended teaching, our teaching team proposes a blended teaching mode of Remote Sensing Principles Course based on the concept of emerging engineering education. This mode is for the problem of learning with difficulty, which is caused by the multi-disciplinary synthesis, strong transformation and wide application of remote sensing courses. The practice shows that the blended teaching mode of Remote Sensing Principles Course based on the concept of emerging engineering education can better solve the problem of learning with difficulty and improve students' professional ability and comprehensive quality.
\end{abstract}

Keywords: emerging engineering education, blended teaching, remote sensing

\section{INTRODUCTION}

The development and the latest trend of engineering education in the world show that the training of engineering talents is highly consistent with the direction of industrial transformation and the trend of industrial development in the future. Besides, the increasingly complex engineering reality will be more closely embedded in the process of engineering education ${ }^{[1]}$. According to the data statistics of "basic situation of National Education Development in 2018" released recently by the Ministry of Education in February 2019, there are 2663 general colleges and universities in China. The number of students enrolled in colleges and universities has added up to 8.2 million in 2019. High-quality engineering scientific and technological professionals are an important guarantee to support the industrial transformation and upgrading, and implement the major development strategies of China ${ }^{[2]}$. In order to meet the requirements of the new economy, serve national strategies, meet the demands of industry and face the development in the future, the construction of emerging engineering education is proposed on the basis of the "Excellent Engineer Education and Training Program". This is a major plan to continuously deepen the reform of engineering education. It also indicates that the reform of higher engineering education in China has entered the implemented stage of the construction of emerging engineering education. Under the background of emerging engineering education, local colleges and universities should play a supporting role in regional economic development and the industrial transformation and upgrading. In addition, local colleges and universities also should cultivate high-quality engineering talents ${ }^{[3]}$. This advances higher requirements for the training of new talents in local colleges and universities, and requires the reform and innovation of curriculum teaching modes. This paper will take the course of " Principles and Applications of Remote Sensing" as an example to explore a new teaching mode of professional courses in colleges and universities on the basis of emerging engineering education.

\section{THE CONNOTATION OF THE CONCEPT OF EMERGING ENGINEERING EDUCATION}

Emerging engineering education aims to take the initiative to deal with the new round of technological revolution and industrial transformation. It offers support and services to a series of national strategies such as innovation-driven development and "made in China 2025"[4]. The connotation of emerging engineering education is the direction of engineering education's reform in China that is proposed on the basis of the new demands of national strategic development and the new situation and requirements of international competition ${ }^{[2,5]}$. The aim of emerging engineering education is to train applied, innovative and compounded engineering professionals who are able to serve national strategies, meet the demands of industrial development, lead the direction of industrial development, and adapt to the development of science and technology in the future. The Ministry of Education actively promotes the construction of emerging engineering education, and fully explores the formation of a Chinese mode and Chinese experience leading the global engineering education, so as to provide help for the construction of strong country in higher education.

From the connotation of emerging engineering education, it can be seen that emerging engineering education has many 
characteristics such as guidance, intersectionality, innovativeness, cross-domain nature and developmental nature. In addition, it's strategic, systematic and open. Emerging engineering education embodies the new concept of engineering education, the new structure of subject and specialty, the new mode of talented people's training, the new quality of education and teaching, and the new system of classified development ${ }^{[2,6]}$

Human beings have entered the era of intelligence. Cloud computing, big data, the Internet of things, artificial intelligence, robot and quantum computing are the most important technical hotspots in this era. The training of talents needs to be oriented to the future to layout the majors of emerging engineering education. The core of the training of professionals in emerging engineering education is the capability which is oriented to the technological revolution and industrial transformation. It should include the abilities of learning, engineering technology, global thinking and innovation.

\section{THE CHARACTERISTICS OF REMOTE SENSING PRINCIPLES COURSE}

The Remote Sensing Principles Course is not only an important subject in the field of geoscience, but also an important subject with rapid development in the field of space science and spatial information. It has distinct curriculum characteristics.

(1) The course is interdisciplinary. Remote sensing theories involve a lot of knowledge in physics, mathematics, geography, cartography, information science, computer science, graphics, etc. In practice, remote sensing also needs some basic knowledge in application fields, such as geology, forestry, soil science, ecology, environmental science, etc. The interdisciplinary nature of this subject is obvious, which requires students to have a certain foundation of multi-disciplinary knowledge. No matter which subject knowledge is missing, it will have an adverse effect on students' correct understanding of the theories of remote sensing.

(2) The course is professional and technical. The content of remote sensing courses includes the basic and professional knowledge of electromagnetic spectrum, remote sensing platform and sensor, digital image, computer classification of remote sensing images and so on. It also includes the technologies of image processing, data fusion, remote sensing interpretation and mapping, as well as the application of remote sensing technology in geology, geomorphology, surveying and mapping, land, environment, water, vegetation, etc.

(3) The course has distinct characteristics of the subject of applied technology. It is mainly based on the applied technology that is closely combined with image recognition, geographic information system and location service production. The technology is updated quickly.

\section{EXPLORATION OF TEACHING MODE BASED ON THE CONCEPT OF EMERGING ENGINEERING EDUCATION}

By analyzing the characteristics of the course of "Principles and Applications of Remote Sensing", we can know that the course is theoretical and difficult for students to learn; It involves a wide range of subjects and requires students to have multi-disciplinary knowledge; It is highly technical, which requires practical training and engineering ability training; The characteristics of the application of information technology require that the course should be closely integrated with production, master cutting-edge technology and meet the demands of society. It's necessary to explore the blended teaching mode based on the concept of emerging engineering education in the teaching practice of this course. (1) It's important to strengthen the construction of the course's connotation under the guidance of the teaching concept of emerging engineering education. Remote sensing is the main supporting technology of spatial information technology. With the popularity of self-enabling mobile terminals, remote sensing has gradually entered various fields of people's life. The construction of this course should cater to the wave of intelligence and be closely combined with cloud computing, big data, Internet of things, artificial intelligence, robot and other hot spots of information technology. It also should embody the new concept of engineering education, so as to adjust the objectives, contents and methods of teaching. What's more, it should explore the new mode of the training on professionals that have remote sensing information technology, and the new system of education and the evaluation of teaching quality.

(2) Designing multi-level practical teaching and strengthening the training of engineering practice ability is necessary. The practical teaching of remote sensing is divided into four levels: the first level is theoretical understanding and confirmatory experiments, such as the understanding of ground objects' spectral characteristics, digital images and their representation, etc. The second level is the basic skills training, which help students master the basic application of related software and the collection and preprocessing of spectral data. Besides, it's helpful for students to learn spectral and geometric correction, enhancement processing and interpretation of remote sensing images. The first level and the second level are mainly completed through experimental teaching. They are mainly carried out around the basic knowledge of remote sensing principles in order to cultivate students' basic steps of experimental operation and their experimental skills. The third level is comprehensive ability training. Given a subject, students make comprehensive use of the knowledge and technology of remote sensing to design the experiment and submit their works. This level is mainly completed through practice. Students not only consolidate their professional knowledge, but also be trained to design experiments and implement projects according to specific problems. This level pays attention to the comprehensive application of knowledge and technology, and the cultivation of engineering ability. The fourth level is the cultivation of innovative ability. It means the research exploration on a certain scientific problem, the focus on cultivation of scientific research thinking and innovative ability, the discovery of and further refining of problems, and the raise of new solutions and methods. The practice of scientific research thinking and innovation ability is implemented by condensing innovative and practical topics through teachers' projects or innovative projects at all levels, thus proposing new methods, solving scientific problems, and publishing 
research results. At this level, practice shows that although only part of the students participate in it, they are very active and have the ability to put forward some worthwhile questions.

(3) It's helpful to give full play to the mutual promotion of teaching and research, and learn cutting-edge technology so as to exercise students' ability. In order to realize the connection with emerging engineering education, it is necessary to pay attention to the emerging engineering majors and track them, such as artificial intelligence, intelligent manufacturing, robot and cloud computing. Under the background that the whole society is constantly aware of the importance of emerging engineering education, it is required to promote teaching through scientific research. We should not only integrate the results of scientific research into teaching in order to supplement and update the teaching content of the course, but also use the scientific research results to supplement cases and presentations on the basis of textbook knowledge. At the same time, bringing the latest scientific research results into class will also enable students to have a better understanding of cutting-edge research in the subject field. It broadens students' horizons, and stimulates students' interest in learning. What's more, we should make use of the scientific research conditions to actively carry out activities of extracurricular scientific research for students. The activities of extracurricular scientific research are not only a favorable means to strengthen teaching practice, but also a necessary way to supply and extend the content of classroom teaching. Therefore, carrying out the activities of extracurricular scientific research plays a vital role in training students' self-learning ability, practical ability, problem-finding ability, problem-solving ability and innovative thinking ability.

(4) It's also important to innovate in collaboration with enterprises, and closely connect with social demands. After all, relying solely on teachers' projects is not enough, and the actual requirements of employers are extensive, which leads to a disconnect between supply and demand. School-enterprise cooperation is the best way to get close to enterprises. The cooperation between schools and enterprises is an effective way to enhance the engineering ability of this major and connect with the demands of the society. First, inviting enterprise experts to colleges to hold lectures on remote sensing, sharing first-line production experience, introducing the trends of industry, and showing the latest software and hardware equipment is necessary. Second, it's meaningful to encourage students to practice in the production front line of production employers to meet the demands of the posts in advance. Strengthening the relationship with enterprises and establishing collaborative teaching between schools and enterprises helps students get in touch with the process of engineering projects during school, thus paving a good way for students to go to work in the future. Third, we are supposed to share engineering cases for teaching. At the same time, teachers can also understand the demands of society and enhance professional competence and quality through the communication with enterprises and on-duty training.

(5) Online and offline blended teaching not only combines theory with practice, but also integrates multidisciplinary knowledge and combines the inside and outside of the campus. The use of online courses, the decompose of the previous process of classroom teaching and the design of online and offline blended teaching mode enable students to learn basic knowledge and operations online, discuss key and difficult points offline, explore scientific problems and exercise hands-on ability, thus improving the efficiency of teaching and learning. Remote sensing courses are multidisciplinary, which makes it difficult for students to learn. Constantly enriching and updating the teaching resources of online courses and making full use of the network to connect the knowledge of multi-disciplines is helpful to solve this problem. In order to improve the quality of practical teaching of remote sensing courses, expand the field of vision and knowledge and train remote sensing engineering professionals with innovative consciousness and innovative ability, we can carry out teaching in connection with the scene of production companies, and reproduce the work scene of production companies through online courses. (6) It's significant to strengthen the assessment of students' ability and give full play to the leading and guiding role of examination. Reforming the current assessment methods and paying attention to the assessment of students' learning process and ability is necessary. The assessment of the learning process includes online learning, discussion and listening in class; The assessment of ability includes examination, the achievements of research projects, and participation in projects and competitions.

\section{CONCLUSIONS}

Multi-disciplinary synthesis, strong transformation and wide application of remote sensing courses have been making it more difficult for students to learn. Teaching practice shows that this problem can be solved better by the blended teaching mode of Remote Sensing Principles Course based on the concept of emerging engineering education. What's more, the blended teaching mode also improves professional ability and comprehensive quality of students. The results of the curriculum operation reports fed back by online courses and the questionnaire on students' satisfaction show students' recognition of the teaching mode. The good achievements obtained in the innovation and competition of college students at all levels have also been determined by employers.

In the future, we will record the teaching process and achievements in detail, track the status of students' learning and development. We will conduct a comprehensive teaching evaluation of the course to promote the sustainable development of the curriculum construction.

\section{ACKNOWLEDGMENT}

This research is supported by the Teaching Reform Research Foundation of Wuhan University of Technology (Grant No. w2018086).

\section{REFERENCES}

[1] Ye Min, Kong Hanbing, Zhang Wei. Emerging Engineering Education: From Idea to Action[J]. Research in Higher Education of Engineering, 2018(1): 24-31(in Chinese). 
[2] Wu Aihua, Yang Qiubo, Hao Jie. The Innovation and Reform of Higher Education under the Leadership of Emerging Engineering Education[J]. Research in Higher Education of Engineering, 2019(1): 1-7,61(in Chinese).

[3] Hu Ruinian, Liu Pu. Research on the Construction and Development Path of "New Engineering" in Colleges and Universities in the New Era[J]. Decision \& Information, 2019(1): 111-122(in Chinese).

[4] Emerging Engineering Education [OL]. https://baike.b aidu.com/item/\%E6\%96\%B0\%E5\%B7\%A5\%E7\%A7\%91/2 0597803 ?fr=aladdin.

[5] Zhong Denghua. Connotations and Actions for Establishing the Emerging Engineering Education[J]. Research in Higher Education of Engineering, 2017(3): 1-6(in Chinese).

[6] Lin Jian. Further Solid Promoting the Construction of New Engineering Disciplines: Some Thinking of the Organization and Implementation of the "Research and Practice Projects of New Engineering Disciplines"[J]. Research in Higher Education of Engineering, 2017(5): 24-37(in Chinese). 